\section{Reason for variable response to tine test}

In comparative studies with the Mantoux test the tine method has shown false-negative rates of between $23 \%$ and $64 \%,{ }^{1-3}$ though studies on highly sensitised tuberculous patients have tended to show a closer correlation. ${ }^{45}$ This inconsistency has remained unexplained by studies of the duration of application, skin temperature, and release of skin tension before removing the tine. I have looked at variability of the tuberculin coating, a factor not previously considered, as a cause of false-negative and diminished responses.

Microscopic inspection of tines shows that there are two characteristic types of tuberculin coating. Either the tip is covered uniformly to a depth of $1.25 \mathrm{~mm}$, or a globule forms some $1.5-1.75 \mathrm{~mm}$ from the tip, leaving the tip itself bare or with diminished coating (figure). All four tines of a disc usually have one or other characteristic coating. Globular tine units ranged from six to 18 in any one container of 25.

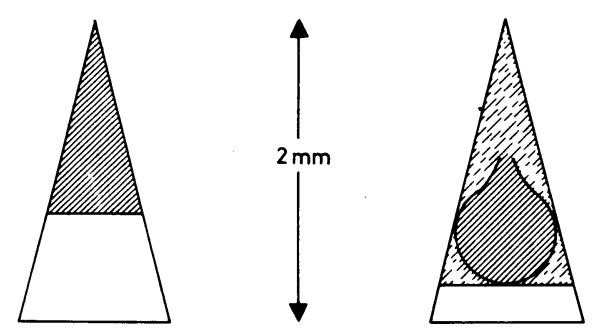

Variable tuberculin coating of tines. Left tine is smooth coated with good tip cover, whereas tuberculin has retracted towards base of right tine, a globule has formed, and tip is poorly covered.

\section{Patients, methods, and results}

A series of tests were carried out on volunteers. Smooth-coated tines were selected from batch No 528-267, and one applied on each arm of 20 persons positive to a Mantoux test ( 5 tuberculin units of purified protein derivative) and read after 48 hours. All reactions were positive and similar between arms on each individual. The sum of the diameters of induration on each arm were $108 \mathrm{~mm}$ and $105 \mathrm{~mm}$.

In the second test, smooth- and globular-coated tines were separated from the same batch and applied to opposite arms of volunteers known to be tuberculin positive. Again 20 paired tests were carried out and read after 48 hours. In seven persons the arms tested with globular-coated tines had a negative reaction, whereas the opposite arms tested with smooth-coated tines were positive. Where globular-coated units produced reactions, these were, with one exception, less than the opposite smooth-coated reaction. The sum of the diameters of induration from 20 smooth-coated tines was $148 \mathrm{~mm}$ and from the 20 globular-coated tines $82 \mathrm{~mm}$. Analysis by the Wilcoxon signed-rank test indicates that dissimilar reactions of this order would arise less than one in 100 times by chance.

In the third test, globular- and smooth-coated tines were selected from batch No 528-267 and distributed randomly in pairs before application to opposite arms of 16 individuals. The distribution and identity of the pairs was unknown to the giver and reader (AJJ). In six cases the globular-coated tines gave negative results but smooth-coated tines gave positive results on the opposite arms. In one strongly sensitised individual, equal reactions of $10 \mathrm{~mm}$ were produced. In eight of the other nine persons, reactions from smooth-coated tines were greater than those from globular-coated tines. The sum of the diameters of induration from 16 smooth-coated tines was $90 \mathrm{~mm}$, whereas it was $48 \mathrm{~mm}$ from the 16 globular-coated tines.

By the Wilcoxon signed-rank test less than $1 \%$ of studies would produce similar differences if there was no difference clinically between coatings. Of the 144 individual smooth-coated tines from the 36 tests in the second and third studies, two produced no visible reaction, but 37 of the 144 individual globular-coated tines produced no visible response.

\section{Discussion}

Correctly applied, tines penetrate $0.8-1.0 \mathrm{~mm}$ and deposit tuberculin when smoothly coated at the tip. On globular-coated tines most of the tuberculin is more than $1 \mathrm{~mm}$ from the tip (often $1.75 \mathrm{~mm}$ ) and is not deposited in the skin. Even a small quantity of tuberculin deposited from globular-coated tines may be sufficient for a response in strongly-sensitised patients, which may account for satisfactory reports from chest and tuberculosis units. When the tine test is used for screening, however, globular coating of some of the tines is likely to lead to false-negative results.

I am indebted to Dr Andrew Johnson, Northern General Hospital, Edinburgh, for suggesting and carrying out the third study, and to $\mathrm{Mr}$ John Wise, physiology department, St George's Hospital Medical School, for statistical guidance.

Photographs of contrasting skin reactions and types of tuberculin coating, and detailed data, are available from the author, Department of Epidemiology and Preventive Medicine, St Mary's Hospital, London W2.

1 Bowder AA, Griffin AL. Tuberculin tines tests on medical wards. Am Rev Respir Dis 1972;105:299-301.

${ }^{2}$ Food and Drugs Administration. Federal Register, part II (skin test antigens). Bethesda: Department of Health, Education and Welfare, 1977.

${ }^{3}$ Welke H, Irsigler GB, Kleeberg HH. The diagnostic value of the tine and Mantoux tests in a general hospital. S Afr Med F 1976;50:2073-6.

4 Snell NJC. A comparison of Mantoux and tuberculin tine testing in a chest unit. Tubercle 1979;60:99-104.

5 Bull PR, Drummond R, Price G. Tine and Mantoux tuberculin tests. Br Med F 1979;i:1712-3.

(Accepted 15 November 1979)

St Mary's Hospital, London W2

J A LUNN, MD, FFCM, senior lecturer in occupational medicine and honorary consultant to the staff and student health service

\section{Lactation and breast cancer}

The belief that lactation reduces the risk of breast cancer is still widely held despite findings to the contrary in a large international epidemiological study. ${ }^{1}$ The continuing confusion prompted us to examine the data on breast-feeding we have collected during a large case-control study of the possible relationship between oral contraceptives and breast cancer.

\section{Patients, methods, and results}

Our methods together with our main findings have been described elsewhere. ${ }^{2}$ In brief, during the period December 1969 to August 1977707 married women aged 16-50 years newly presenting with cancer of the breast were interviewed at eight teaching hospitals in London and Oxford and asked about their medical, obstetrical, menstrual, social, and contraceptive histories. Inquiries were also made about the duration of breast-feeding of each child. A control group of 707 married women suffering from various acute medical or surgical disorders or who had been admitted to hospital for certain elective surgical procedures were similarly interviewed. They were matched with the patients with breast cancer for age (within five-year groups except for the first 90 case-control pairs, who were matched within \pm 5 years), parity (within groups $0,1-2$, and 3 or more term births), and hospital of admission.

For the present analysis the matching was broken and the cases and controls were classified by exact parity (para 1 -cases 121 , controls 133 ; para 2-cases 256 , controls 244 ; para 3-cases 142 , controls 123 ; para 4-cases 58 , controls 54). Women with a parity higher than 4 were few in number and were therefore omitted from the analysis. Since the first pregnancy seems to be of special importance in relation to the risk of breast cancer we concentrated initially on the feeding of the first child. Subsequently, we also considered the feeding of other children. Three main measures of lactation were taken into account: whether the woman had breast-fed at all, whether she had fed for more than 16 weeks, and the mean duration of feeding. The findings, considering the first child alone and then all children together, are summarised in the table. The differences between the breast cancer patients and the controls are small and inconsistent and none approaches statistical significance. Adjustment of the data for any possible 
Breast-feeding practices of women with breast cancer and control women

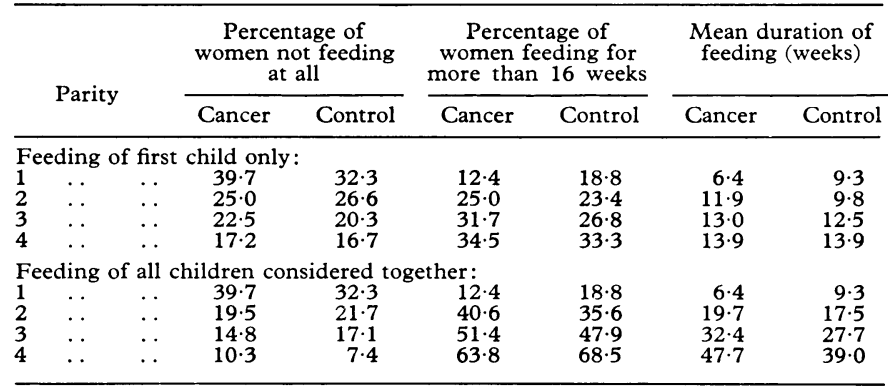

confounding effect of age at first-term birth, using the method of Mante and Haenszel, ${ }^{3}$ produced only minor changes. Further analyses were carried out using different measures of lactation and examining various patterns of feeding (for example, first and second child fed, later children not fed). In none was there any significant evidence that lactation is related in any way to the risk of breast cancer.

\section{Comment}

Our data on lactation and breast cancer are extensive and relate exclusively to married women up to 50 years of age. There are two possible advantages in concentrating attention on younger women. Firstly, their recall of breast-feeding practices is likely to be better. Secondly, if lactation has any relevance to the risk of breast cancer it might perhaps be more likely to express an effect in younger women. In the event, like MacMahon and his colleagues, ${ }^{1}$ we have found no evidence for such a relationship.

We thank Miss Keena Jones, Mrs Moya Simmonds, and Mrs Judith Young for interviewing the patients.

${ }^{1}$ MacMahon B, Lin TM, Lowe CR, et al. Lactation and cancer of the breast. A summary of an international study. Bull WHO 1970;42:185-94.

2 Vessey MP, Doll R, Jones K, McPherson K, Yeates D. An epidemiological study of oral contraceptives and breast cancer. $\mathrm{Br} M e d \mathcal{F}$ 1979;i:1755-8.

${ }^{3}$ Mantel N, Haenszel W. Statistical aspects of the analysis of data from retrospective studies of disease. $\mathcal{F}$ Natl Cancer Inst 1959;22:719-48.

(Accepted 15 November 1979)

University of Oxford, Department of Social and Community Medicine, Oxford OX1 3QN

A KALACHE, MD, MFCM, clinical lecturer

M P VESSEY, MD, FRCPED, professor

K MCPHERSON, MA, PHD, university lecturer

\section{DDAVP in the prevention of headache after lumbar puncture}

Unpleasant side effects of lumbar puncture include headache, nausea, and vomiting. Continuing leak of cerebrospinal fluid (CSF) through the hole in the theca is probably significant. Low CSF pressure may result in traction on pain-sensitive structures such as arteries and veins. An antidiuretic agent tends to retain fluid in extracellular spaces, including CSF. Administration of vasopressin should ameliorate these side effects. Vasopressin is expensive, scarce, and has unpleasant pressor side effects such as diarrhoea, abdominal cramps, and sweating. Aziz $e t a l^{1}$ found that vasopressin injection reduced the frequency of side effects of lumbar puncture but that $27 \%$ of the patients had diarrhoea, abdominal cramps, and sweating of varying severity. The incidence of headache found by Aziz et al was $26 \%$ and that found by Wolff $^{2}$ in four large series was $25 \%$. Thus a group of patients given vasopressin to prevent the side effects of lumbar puncture will probably not show net benefit. The synthetic vasopressin analogue 1-desamino-8-D-arginine vasopressin (DDAVP) is free of pressor side effects but has significant antidiuretic activity. The results of Aziz et $a i^{1}$ imply that prophylaxis with DDAVP would benefit patients having lumbar puncture.

\section{Patients, methods, and results}

Fifty patients requiring diagnostic lumbar puncture were studied. Patients with cardiac failure, ischaemic heart disease, renal failure, hypertension, or taking corticosteroids were excluded lest even mild fluid retention might be harmful. DDAVP or isotonic saline was given on a random double-blind basis, each dose of DDAVP being $4 \mu \mathrm{g}$. One ampoule was given intramuscularly every 12 hours, beginning four hours before lumbar puncture in the lateral position. In each case an 18- or 20 -gauge needle was used to withdraw $5 \mathrm{ml} \mathrm{CSF}$. Patients then rested in bed, apart from toilet purposes, for 24 hours. Blood pressure was recorded every 12 hours. Serum urea, electrolytes and osmolality together with urine osmolality were measured at the time of giving and four hours after the first and third ampoules. Fluid intake was maintained at about $2 \mathrm{l} / 24 \mathrm{~h}$. Headache, nausea, vomiting, and other symptoms were recorded 12-hourly for 48 hours after the first ampoule-that is, until 24 hours after the patient was fully mobile. When headache was reported the patient indicated its severity by the analogue method. The result was recorded as a percentage score and then classified as "mild" (0-33\%), "moderate" (34-66\%), or "severe" (67-100\%). Six patients in each group of 25 patients had headache after lumbar puncture-an incidence of $24 \%$, which corresponds with the experience of others.

The record (table) of the total number of headaches of given severity reflects duration as well as severity because the same headache lasting 24 hours will be recorded at least twice, and so on. The combined frequencies of mild and moderate headaches examined by the Fisher exact probability test gives a value of 0.0097 (significant). No side effects were attributable to treatment. Serum sodium concentrations fell somewhat in patients given DDAVP but never below $130 \mathrm{mmol}(\mathrm{mEq}) / 1$. No patient's blood pressure rose significantly.

Total number of headaches of given severity recorded by 50 patients given $D D A V P$ or placebo during diagnostic lumbar puncture

\begin{tabular}{|c|c|c|c|c|c|c|c|c|}
\hline \multirow{2}{*}{\multicolumn{2}{|c|}{ Drug }} & & & & \multirow{2}{*}{$\begin{array}{l}\text { No of } \\
\text { patients }\end{array}$} & \multicolumn{3}{|c|}{ Headache } \\
\hline & & & & & & Mild & Moderate & Severe \\
\hline $\begin{array}{l}\text { DDAVP } \\
\text { Placebo }\end{array}$ & $\because$. & $\therefore$ & 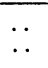 & 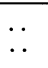 & $\begin{array}{l}25 \\
25\end{array}$ & $\begin{array}{l}9 \\
5\end{array}$ & $\begin{array}{l}3 \\
2\end{array}$ & $\begin{array}{l}0 \\
6\end{array}$ \\
\hline
\end{tabular}

\section{Comment}

This study confirms that DDAVP does not affect the incidence of headache after lumbar puncture but disability is significantly lessened. We gave DDAVP parenterally but it could be given intranasally instead in a higher dose $(20 \mu \mathrm{g})$. Giving DDAVP for an established headache after lumbar puncture is probably worth trying and safe, but further investigation is required. It also merits trial in other clinical situations associated with lumbar puncture including myelography, lumbar air encephalography, and epidural anaesthesia.

We thank Ferring Pharmaceuticals for supplying DDAVP and placebo in a form suitable for this trial, our colleagues who permitted their patients to take part, and Dr S Hansen for statistical analysis.

1 Aziz H, Pearce J, Miller E. Vasopressin in prevention of lumbar puncture headache. Br Med f 1968;iv:677-8.

2 Wolff HG, Headache and other head pain. 2nd ed. New York: Oxford University Press, 1963:112.

(Accepted 1 November 1979)

Institute of Neurological Sciences, Southern General Hospital, Glasgow G51 4TF

J M A COWAN, MRCP, registrar in neurology

W F DURWARD, MRCP, consultant neurologist

H HARRINGTON, MRCP, registrar in neurology

Royal Infirmary, Glasgow G4 OSF

J H JOHNSTON, MRCP, senior registrar in medicine

Camberley, Surrey

B DONOVAN, MB, general practitioner

\section{Correction}

\section{Immunoreactive calcitonin in leukaemia}

An error occurred in this article by Dr C J Hillyard and others ( 1 December $1979, \mathrm{p} 1392)$. The key in the figure legend should have read " $O=$ studied in transformation. $O=$ studied in chronic phase." 